Book Review

\title{
Improvisation, Creativity, and Consciousness: Jazz as Integral Template for Music, Education, and Society
}

\author{
Edward W. Sarath \\ State University of New York Press, 2013 \\ ISBN 978-1438447216 \\ 487 Pages
}

\section{Reviewed by Michael Dannhauer}

Musician, educator, and author Edward W. Sarath is among the first to implement contemplative practices and Integral Theory into higher education, facilitating a conceptualized understanding of the human condition and the phenomenon of consciousness. His book Improvisation, Creativity, and Consciousness: Jazz as Integral Template for Music, Education, and Society offers a deep insight into his vision and concepts, which link artistic studies and music education with personal growth and societal change.

\section{Encountering Edward Sarath's Vision}

Sarath's innovative educational ideas first came to life on a broader scale when, at the turn of the century, he introduced a Bachelor of Fine Arts in Jazz and Contemplative Studies at the University of Michigan School of Music, Theatre, and Dance. The curriculum combined extended coursework in jazz and musical tuition with contemplative practices such as meditation, as well as other subjects such as psychology, philosophy, religion, and sociocultural studies.

At the University of Michigan, Sarath also established the campus-wide Program in Creativity and Consciousness Studies (PCCS) which extended his vision of integrating spiritual inquiry into academic and artistic studies, both in and beyond the realm of music education. Apart from making recourse to a solid foundation of research supporting the physiological, mental, and behavioral benefits of contemplative practices, Sarath also proposes "that the next frontier in higher education will involve probing the innermost dimensions of the knowerconsciousness - and the mission of the PCCS is to illuminate this common core to all fields of study. At which point, an adequate conceptual framework is needed to guide the transformation process" (Sarath, Improvisation, 1).

This sort of conceptual framework is presented in his full-length monograph Improvisation, Creativity, and Consciousness. The title points to the author's foundational thesis that an indepth engagement with creativity and consciousness in tandem with the practice of the arts, and jazz in particular, can facilitate a doorway to insight and self-exploration. This can subsequently be used as a template "for crossing the exterior-interior divide that could be applied across fields, and which" in Sarath's words "represents the future of education" (Sarath, "Improvisation," 11).

Furthermore, he posits that this paradigmatic shift in educational systems is particularly urgent as the world is currently threatened by an unprecedented set of challenges, as well as opportunities for progress. Sarath therefore calls for a "new evolutionary plateau" (2). 
As means for a conceptualization and operationalization of this mission for educational and societal change, Sarath deploys the framework of Integral Theory. This philosophical as well as spiritual approach to holistically understand intra- and interpersonal development as well as the basic structures, patterns, and interplay of all these phenomena was first introduced by Ken Wilber in the late 1970s in his book The Spectrum of Consciousness. This has subsequently been taken up, expanded upon, and refined by numerous academics and authors. Sarath's original contribution is found in the theory's extensive application to the field of music education.

Taking up his condensed definition, "Integral Theory maps the inner-outer dimensions of human being and cosmic wholeness, the processes that promote navigation and integration of this wholeness, and the evolutionary dynamics by which systems evolve over time" (24). Behind the development of his Integral Theory stands an ambitious goal: the unifying effects of contemplative and artistic practices, are to facilitate the merger of the personal, individuated self and the transcendent, cosmic self into one integrated whole. From a traditional scientific and dualistic standpoint, Sarath's claim of the possibility of a "nondual relationship between individual consciousness and cosmic wholeness" (16) constitutes a major challenge which reinforces the need of applying a consistent theoretical framework to assess Sarath's theses and conclusions.

\section{Part I. Creativity, Consciousness, and the Integral Vision}

Using Integral Theory as an epistemological scaffold, the first chapters of his book give an extended introduction to basic concepts including the AQAL ${ }^{1}$ Framework and the theory of Integral Evolutionary Dynamics. In so doing, he also explains their implications for the learning, teaching, practicing, and researching of improvisation and meditation. He writes that the integral perspective enables a non-judging juxtaposition of a subjective, contemplative approach with inter-subjective, collaborative creative interactions and objective, scientific research. This potential to bridge the widely perceived divide between objective and subjective ways of learning about the world emphasizes the necessity for an educational approach which incorporates spirituality, art, and science and which integrates them into a single, synergetic developmental continuum. In this context, Sarath recognizes improvisational musical practice and meditation as being complementary pathways to the same goal of reaching a higher level of physiological, mental, spiritual, and inter-personal wholeness. He writes that these elements "work in tandem to traverse and integrate the inner-outer, creativity-consciousness spectrum" (121).

\section{Part II. Jazz: An Integral Reading}

The second part of the book offers an in-depth look at improvisatory jazz music, its current place in traditional music education, and its transgressive potential for individual and societal progress.

As evidence for the close relationship between contemplative practices and improvisatory jazz music, Sarath refers to numerous renowned jazz artists like John and Alice Coltrane, John McLaughlin, Wayne Shorter, or Herbie Hancock "who engaged with meditation and related methodologies for growth of creativity and consciousness in order to integrate the transcendent experiences glimpsed during their musical excursions more fully into their work and lives" (4). Coming from this observation, Sarath elaborates further on jazz music's unique potential to enhance artistic and personal growth, as well as its predisposition to aid with "parts to whole" (51) integration. As examples for this, he mentions musical concepts such as swing time feel and modality as possible change agents, which are potentially conducive to a transformation of 
consciousness.

In this context, he also highlights the limitations of conventional music education by criticizing the prevalent orientation towards a scientific, objectivist paradigm and the subsequent marginalization of subjective and inter-subjective realities. He proclaims that a music education that is limited to the interpretation and analysis of notated scores must fall short of its potential since it denies students the possibility of pursuing their artistic practice together with personal and inter-personal growth. Sarath draws the conclusion that this traditional approach poses the risk of losing the integral and transformative potential of jazz.

He therefore advocates an expansion of the educational focus beyond the interpretation and analysis of scores and towards improvisation and composition, thereby correcting for the common neglect of the synergetic interplay of these practices and their connection with collective consciousness. According to Sarath, peak experience and innovative creative output are always a product of merging individual skills and inspiration with a transcendental dimension that exceeds the narrow approach of understanding artistic performance at the level of isolated individuals. Subsequently, the author opens up a new perspective on the locus of knowledge and creativity by centering on the interpersonal and connecting it with a higher level of consciousness development.

Another point of criticism addressed by the author is the prevailing ethnocentric focus entrenched in most Western professional musicians who have gone through tertiary education and who have been exposed to accompanying parochial curricula and educators' biases. In Sarath's estimation, the integration of non-European music traditions and practices into education programs is crucial to broadening musical horizons and empowering students in finding their way in a globalized world characterized by rapid cultural change.

\section{Part III. Change}

In the third and final section of his monograph, Sarath reveals the structural, pedagogical, and content-related implications of his theory, aiming towards an integral shift within music schools, the general education system, and global society.

In addressing the question of what the music school of the future might look like and how it might differ from the current model, Sarath neatly juxtaposes the various features of a conventional music school and the respective characteristics of an integral music school. This condensed form of comparing the two models grants the reader a clear overview of their differentiation along the relevant dimensions of music education including central artistic profiles, organizational structures as well as the use of technology.

The author then presents three change strategies detailing possible changes in curricula and the learning environment. Along with these, he offers practical guidelines and illustrates possible obstacles for educators. This again underlines Sarath's position as an educational pioneer in proposing what is, to my knowledge, the first framework for an integral transformation of music schools.

In the following chapter, he makes an appeal to educational institutions at large, which reads as an appeal for change towards integral forms of education. This transformation should be accompanied by a change in discourse which includes the implementation of a framework known as Deep Inquiry. This method consists of examining the educational project as a whole, from the technical specifics to the most general factors that affect it. Among the aspects 
considered are the analysis of the specifics of a discipline, broader questions involving the fundamental educational idea of the institution as well as the inquiry into the nature of the human being who is setting out on the educational journey. Deep Inquiry again highlights the importance of a holistic idea of education and the integration of science and the arts, spirituality and rationality as well as creativity, and consciousness into one curriculum.

In a final tour de force, Sarath transfers his blueprint for educational innovation to an even larger scale, using it as an approach for tackling impending twenty-first century challenges. From his perspective, in order to successfully face the potential global crises ahead, humanity should use the logic of action of a jazz group. The author postulates that "the improvising ensemble called 'humanity'-consisting of over seven billion members-needs to invoke new ways of thinking and action as it navigates its way through the 'chord changes' of unprecedented complexity and scope that are unique to our time" (397). In this context, the jazz ensemble which creates, communicates, and joins up as one integrated whole is brought forth as a template and systemic role model for successful problem solving and intra- and interpersonal thriving.

To sum up Sarath's text, through its theoretical concepts and their practical implications, notwithstanding the radical timbre they might carry in the ears of newcomers to the idea of Integral Theory and Consciousness Studies, should be considered a ground-breaking piece of work inside and outside the field of music education. In this it goes beyond making a valuable contribution to the current discourse concerning a paradigmatic shift in higher education. His propositions integrate traditional approaches with innovative teaching and learning methods and speak of a mindset that brings together the objective lens of the academic with the subjective perspective of the artist and the transcendental view of the meditator. The result is a bold sketch, at times very much like a well-played improvisation, of how to merge the artistic, emotional, social and spiritual dimension on a pathway to personal and societal flourishing.

\section{Notes}

1 “All quadrants, lines, levels, states and types" (Sarath, Improvisation, 26).

\section{Works Cited}

Sarath, Edward W. "'Improvisation, Creativity, and Consciousness' by Ed Sarath." The Buddha, PBS, 8 Apr. 2010, http://www.pbs.org/thebuddha/blog/2010/apr/8/improvisationcreativity-and-consciousness-ed-saral. Accessed 30 Sep. 2018.

---. Improvisation, Creativity, and Consciousness: Jazz as Integral Template for Music, Education, and Society. State University of New York Press, 2013.

Wilber, Ken. The Spectrum of Consciousness. Quest Books, 1993. 